\title{
El héroe épico: una perspectiva comparada
}

\author{
The epic hero: a comparative perspective
}

\author{
Roberto Morales Harley ${ }^{1}$
}

Fecha de recepción: 28-5-2019

Fecha de aprobación: 12-8-2019

\begin{abstract}
Resumen
El artículo ofrece un análisis del héroe épico, como categoría distinta del héroe mítico, en la épica guerrera griega (Ilíada) y en la épica guerrera sánscrita (Mahābhārata). La premisa metodológica que guía la investigación es que los diversos planteamientos existentes sobre el héroe resultan muy generales para su aplicación a los héroes épicos, especialmente a los de la épica guerrera. El modelo teórico sobre el que se apoya el estudio es una combinación de la morfología heroica (Bauzá, 2004) y de los elementos del relato (Mendoza, 1995). La principal contribución es una tipología de las doce características del héroe épico de la épica guerrera. Palabras clave: héroe, héroe épico, héroe mítico, épica guerrera griega, épica guerrera sánscrita.
\end{abstract}

\begin{abstract}
The paper offers an analysis of the epic hero, as opposed to the mythical hero, in Greek warrior epics (Iliad) and Sanskrit warrior epics (Mahābhārata). The methodological premise that guides the investigation is that the various existing approaches to the hero are too general for their application to epic heroes, particularly to those of the warrior epics. The theorical bases on which the study stands are a combination between the heroic morphology (Bauzá, 2004) and the narrative elements (Mendoza, 1995). The main contribution is a typology of the twelve characteristics of the epic hero in warrior epics.

Key Words: Hero, Epic Hero, Mythical Hero, Greek warrior epics, Sanskrit warrior epics.
\end{abstract}

Profesor de la Escuela de Filología, Lingüística y Literatura de la Universidad de Costa Rica. Costa Rica. Correo: roberto.moralesharley@ gmail.com 


\section{Introducción}

Héroe es una palabra procedente del latín y originaria del griego. Por tal razón, para su abordaje resulta pertinente una revisión etimológica y lexicográfica en español, en latín y en griego. El Diccionario de la Lengua Española (2014) brinda la siguiente información sobre la voz española héroe:

\section{héroe, ína}

Del lat. heros, -ōis, y este del gr. ท̆ $\rho \omega$ s hếrōs; la forma

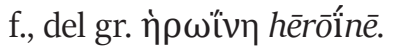

1. m. y f. Persona que realiza una acción muy abnegada en beneficio de una causa noble.

2. m. y f. Persona ilustre y famosa por sus hazañas o virtudes.

3. m. y f. En un poema o relato, personaje destacado que actúa de una manera valerosa y arriesgada.

4. m. y f. Protagonista de una obra de ficción.

5. m. y f. Persona a la que alguien convierte en objeto de su especial admiración.

6. m. En la mitología antigua, hombre nacido de un dios o una diosa y de un ser humano, por lo cual era considerado más que hombre y menos que dios; p. ej., Hércules, Aquiles, Eneas, etc. (Real Academia Española, 2014).

Un héroe, pues, puede ser una persona (acepciones 1, 2 y 5) o un personaje (acepciones 3, 4 y 6). En el caso de las personas, la definición del heroísmo puede ir asociada a la acción heroica (acepción 1), a quien la realiza (acepción 2) o a quien reconoce que alguien más la ha realizado (acepción 5). Para los personajes, se menciona la mitología como marco de referencia (acepción 6), la literatura como ámbito de aplicación (acepción 4) y algún género literario en particular (acepción 3).
Segura (2003, p. 337) provee estos significados para la voz latina hērōs: "Hērōs, -ōis [gr. hếrōs, hếrōos, 'semidiós', 'jefe militar épico'], m. héroe, semidiós, de la edad mítica [epíteto de los personajes épicos] || [fig.] referente a un hombre célebre". En latín, la oposición es, entonces, entre un sentido literal y uno figurado, los cuales explican, respectivamente, los sentidos de personaje y persona en español. El sentido literal combina los dos referentes primordiales de la voz latina: la mitología y la literatura épica.

Pabón (1999, p. 288) registra estos usos para el término

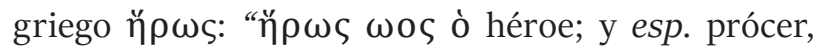
campeón, adalid; héroe, semidiós y esp. patrono de un país, comunidad ciudad, etc. || ADJ. heroico, excelso, noble, generoso [de nacimiento, sentimientos, hechos, etc.]". Así, en griego, se aprecian dos pares de opuestos: acciones y emociones, como las dos vertientes de la heroicidad; dioses y hombres, como los dos extremos entre los cuales se articula el héroe. El héroe, desde su etimología griega, se evidencia como mediador entre aspectos ambiguos.

En esta tradición occidental, el héroe es, en consecuencia, una persona o un personaje de la mitología o de la literatura, especialmente épica, que media entre acciones y emociones, entre humanos y divinidades. Para efectos de la presente propuesta, se distingue entre el héroe mítico como categoría general, cuyo marco de referencia es la mitología, entendida como patrimonio común del pueblo, y el héroe épico como categoría particular, cuyo ámbito de aplicación es la literatura épica como producción artística concreta. Dos principios básicos rigen esta diferenciación: 1) todos los héroes épicos son héroes míticos, pero no todos los héroes míticos son héroes épicos; y 2) todos los héroes épicos son personajes de los poemas épicos, pero no todos los personajes de los poemas épicos son héroes épicos.

En relación con el primer principio (todos los héroes épicos son héroes míticos, pero no todos los héroes míticos son héroes épicos), conviene enfatizar que, por el hecho de ser héroes épicos, los personajes no dejan de ser héroes míticos. Por ejemplo, en la antigua Grecia, Aquiles (protagonista de la Ilíada) y Odiseo (protagonista de la Odisea) son héroes míticos y, además, héroes épicos; y, en 
la antigua India, Arjuna (protagonista del Mahābhārata) y Rāma (protagonista del Rāmāyaṇa) son héroes míticos y además héroes épicos, pero Manu (héroe progenitor de la humanidad) es solo un héroe mítico.

También hay que recalcar que no todos los héroes míticos fuera de la categoría de héroes épicos poseen la misma naturaleza. Así como el héroe épico es una subclase del héroe mítico, del mismo modo, existen otras subclases de héroes literarios. Por ejemplo, en Grecia antigua, hay héroes líricos, como Hierón (destinatario de la primera Olímpica de Píndaro); héroes trágicos, como Edipo (protagonista del Edipo Rey de Sófocles); héroes cómicos, como Trigeo (protagonista de La paz de Aristófanes); o héroes novelísticos, como Dafnis (protagonista de la novela Dafnis y Cloe de Longo). Y, en India antigua, hay héroes dramáticos, como Dusyanta (protagonista de El reconocimiento de Śakuntalā de Kālidāsa); o héroes fabulísticos, como Naravāhanadatta (protagonista de El océano de ríos de cuentos de Somadeva). Aunque no protagonicen un poema épico, todos estos personajes median entre aspectos ambiguos.

Con respecto al segundo principio, (todos los héroes épicos son personajes de los poemas épicos, pero no todos los personajes de los poemas épicos son héroes épicos), resulta pertinente señalar que, por el hecho de aparecer en un poema épico, los personajes no devienen automáticamente en héroes épicos. Así, Tersites (personaje de la Ilíada) y Adhiratha (personaje del Mahābhārata), pese a que figuran en poemas épicos, no son héroes de este tipo. Como mediadores entre lo humano y lo divino, los héroes épicos pertenecen a un estrato social elevado: son nobles guerreros, más importantes que los mortales, pero no tanto como los inmortales. Entre los pueblos indoeuropeos, la nobleza guerrera ocupa una posición privilegiada, la segunda función (fuerza), por debajo de la primera (soberanía y religión) y por encima de la tercera (bienestar humano y fecundidad) (Mendoza, 1995, p. 132).

En los siguientes apartados, se desarrollan tres elementos: la teoría sobre el análisis comparativo del héroe, la figura del héroe mítico y la figura del héroe épico. Para el héroe épico, se trabaja con la épica griega y la épica sánscrita, los dos mayores exponentes de la épica indoeuropea. Finalmente, se proponen las características propias del héroe épico, como categoría distinta del héroe mítico.

\section{La teoría: el héroe y el análisis comparativo}

Bauzá (2004, p. 23-37), con su "morfología heroica”, y Mendoza (1995, p. 129-140), con sus "elementos del relato", constituyen los referentes teóricos para delimitar la figura del héroe épico. Bauzá (2004, p. 7) parte de la premisa de que morfología, además de 'estudio de las formas', puede ser entendida como 'estudio de las estructuras' y resume, así, una serie de "invariantes" o rasgos distintivos de la morfología heroica. Su obra incluye, en extenso, veintidós rasgos retomados de los planteamientos de Raglan y, en resumen, tres rasgos de su propia formulación. Los principales rasgos funcionales, en versión extendida, son los siguientes:

1. La madre del héroe es una royal virgin.

2. Su padre es un rey.

3. El rey suele tener cierto parentesco con la que sería su esposa.

4. Las circunstancias de la concepción del héroe son inusuales.

5. Al nacer es considerado como hijo de un dios.

6. Su nacimiento está rodeado de la posibilidad de ser muerto por su padre o por su abuelo materno.

7. Pero el niño es arrebatado misteriosamente (tema del abandono o expositio).

8. Es criado por padres adoptivos en un país lejano.

9. Nada se dice sobre su niñez.

10. El joven, al llegar a la edad viril, regresa a su hogar o alcanza un reino. 
11. Obtiene la victoria en una lucha despareja con un rey o un gigante, o con un dragón u otra fiera real o ficticia.

12. Tras la victoria, como recompensa, se casa con la princesa que, a menudo, es la hija de su predecesor.

13. Por ese acto alcanza el reino.

14. Durante un tiempo gobierna sin inconvenientes.

15. Prescribe leyes.

16. Pero, sin que muchas veces haya un motivo visible, pierde el favor de los dioses o de sus súbditos.

17. Es sacado del trono y expulsado de la ciudad.

18. Halla una muerte misteriosa.

19. La mayor parte de las veces esta sucede en la cima de una colina.

20. Su hijo no lo sucede en el reino.

21. Su cuerpo no es sepultado.

22. Sin embargo, el héroe tiene una o muchas tumbas en las que se le celebra culto.

(Bauzá, 2004, p. 24-25, a partir de Raglan).

Si se toma como paradigma de héroe épico a Aquiles, para la antigua Grecia, y a Arjuna, para la antigua India, al aplicar estos rasgos funcionales, son muchos los puntos de desencuentro. Aquiles es hijo del rey Peleo y la diosa Tetis, mientras que Arjuna es hijo del dios Indra y la noble Kuntī (ambos cumplen los rasgos 1 y 2). En ninguno de los dos hay parentesco directo entre los padres (ambos incumplen el rasgo 3), aunque en los dos hay una concepción inusual (ambos cumplen el rasgo 4). Aquiles es el hijo de una divinidad (cumple el rasgo 5), pero Arjuna es la encarnación de una divinidad (incumple el rasgo 5). Ninguno de los dos es amenazado por sus predecesores, abandonado a su suerte o criado por padres adoptivos (ambos incumplen los rasgos 6, 7 y 8). La niñez de los dos reviste escasa importancia (ambos cumplen con el rasgo 9). Aquiles opta por la gloria en lugar del regreso (incumple el rasgo 10), mas Arjuna sí regresa (cumple el rasgo 10). Los dos triunfan en batalla, quizás el rasgo más propio del héroe épico (ambos cumplen el rasgo 11).

El tema de la recompensa también resulta muy apropiado para la épica: Aquiles obtiene a Briseida y Arjuna consigue a Damayantī (ambos cumplen con el rasgo 12). Ninguno de los dos alcanza un reino, gobierna un pueblo, prescribe leyes o dirige súbditos, pues estas metas son más apropiadas para el rey épico, como Agamenón o Yudhișthira, que para el héroe épico, como Aquiles o Arjuna (ambos incumplen los rasgos 13, 14, 15 y 16). Aquiles no es exiliado (incumple el rasgo 17), pero Arjuna sí (cumple el rasgo 17). Los dos mueren de manera poco heroica (ambos cumplen con el rasgo 18), si bien no en la cima de una colina (ambos incumplen el rasgo 19). Ni Neoptólemo, el hijo de Aquiles, ni Abhimanyu, el hijo de Arjuna, heredan el trono (ambos cumplen con el rasgo 20). Aquiles recibe culto (cumple los rasgos 21 y 22), no así Arjuna (incumple los rasgos 21 y 22). Así, de las veintidós invariantes, Aquiles cumple once e incumple otras once, mientras que Arjuna cumple diez e incumple doce. Pese a un recuento poco favorable, son dignos de atención dos elementos: el combate y la recompensa.

Siguiendo con la morfología heroica, los principales rasgos funcionales, en versión resumida, son tres:

1. Culto público

2. Muerte involuntaria

3. Combate

(A partir de Bauzá, 2004, p. 23-37).

Para los héroes, "el rasgo distintivo que los caracteriza es haber recibido culto público, lo que los diferencia del común de los mortales, que recibían uno de carácter 
privado; también por el tipo de culto, los héroes guardan distancia respecto de los dioses" (Bauzá, 2004, p. 26). De este modo, la primera característica del héroe sería su condición intermedia, en tanto ente superior a los humanos, pero inferior a las divinidades: si los mortales recibían culto privado, los héroes eran objeto de culto público y, si los dioses conseguían sacrificios matutinos, de víctimas blancas orientadas hacia el cielo y parcialmente quemadas, los héroes en cambio, obtenían sacrificios vespertinos, de víctimas negras, colocadas sobre la superficie y completamente consumidas por el fuego.

El culto público, el rasgo principal de la morfología heroica, es también el más general. Por el contrario, la muerte involuntaria y el combate son rasgos más específicos. En otras palabras, mientras que el culto público es propio de todo héroe mítico, la muerte involuntaria y el combate son inherentes, respectivamente, al héroe trágico y al héroe épico. El propio Bauzá (2004, p. 30) afirma, con respecto al primer rasgo que "la muerte involuntaria -la conocida figura del 'phónos akoúsios'- es una circunstancia que normalmente les acaece a los héroes trágicos -Heracles, Edipo, Áyax, Aristeo, son los ejemplos más conocidos-”. En relación con el combate, este estudioso señala lo siguiente:

La grandeza del héroe radica en que al combatir arriesga su vida y, por ese hecho, el combate se convierte en la prueba esencial de su existencia. En este aspecto Aquiles se presenta como el héroe prototípico, si uno atiende a la disyuntiva que se le plantea y a la elección voluntariamente asumida por el héroe (Bauzá, 2004, p. 31).

Combate, muerte (voluntaria) y culto representan, cronológicamente, los tres estadios del héroe épico. De forma paralela, recompensa, honor y gloria son, respectivamente, los tres móviles que impulsan al héroe épico: combate por su recompensa, muere por su honor y es reverenciado para su gloria. Dicho de otro modo, vive luchando por lo que quiere, muere defendiendo lo que tiene y sobrevive en un plano distinto. En este sentido, los puntos de encuentro con Aquiles y Arjuna son mayores: Aquiles pelea en Troya y Arjuna en Kurukșetra, Aquiles perece vengando a Patroclo y Arjuna acompañando a
Yudhișțhira, Aquiles consigue un recuerdo eterno y Arjuna un más allá temporal, con la posibilidad de trascender.

El motivo del culto tras la muerte del héroe se enmarca en el ámbito de las creencias religiosas del pueblo al que el héroe pertenece. Para el caso indoeuropeo, Mendoza (1995, p. 129) parte de la premisa de que "los pueblos que comparten una misma lengua comparten una cultura común”. Así, explica los elementos culturales comunes entre los distintos pueblos de origen indoeuropeo a partir de una hipotética cultura indoeuropea. Además, señala que el estudio comparativo de dicha cultura desde la óptica del fenómeno religioso ha atravesado, históricamente, tres etapas, las cuales se caracterizan por sendos enfoques:

\section{Estudio léxico \\ 2. Ideología \\ 3. Elementos de relato \\ (A partir de Mendoza, 1995, pp. 130-134).}

En primer lugar, el estudio léxico de la religión indoeuropea llevó a la conclusión de que "los dioses son inmortales y celestes mientras que por el contrario los hombres son mortales y terrestres" (Mendoza, 1995, p. 130). A manera de ejemplo, la forma *deiwos, de donde proceden tanto el griego Zeús (Zeus) como el sánscrito devah (dios), se remonta a la raíz *dyeu- (Watkins, 2000, p. 22), que significa 'brillar'. A su vez, la forma ${ }^{*} m r_{\circ}-t o-$, que da origen al griego ßротós (mortal) y al sánscrito mritam (muerte), deriva de la raíz *mer- (Watkins, 200o, p. 55), cuyo sentido es el de 'morir'.

En segundo lugar, el acercamiento ideológico a la religión indoeuropea permitió la identificación de un patrón tripartito de funciones sociales: soberanía y religión, fuerza, bienestar humano y fecundidad. En opinión de Mendoza (1995):

Esta concepción tripartita del mundo propia de los IE se ve reflejada en la frecuencia de las tríadas divinas, en los planteamientos de las hazañas de 
sus héroes, en la organización de la sociedad o incluso más sutilmente en una visión subyacente general de cuál debería ser el Orden adecuado en muchos campos de la vida humana (p.132).

Con respecto a la ideología heroica, para el Mahābhārata, Dumézil (1977, p. 65) relaciona a los cinco hermanos Pānduvas con las tres funciones indoeuropeas: Yudhișțira, encarnación del dios Dharma y representante de la clase brāhmaṇa (sacerdote), corresponde a la primera función, la soberanía y la religión; Bhīma, encarnación del dios Vayu, y Arjuna, encarnación del dios Indra, son los dos representantes de la clase knatriya (noble, guerrero) y corresponden, así, a la segunda función, la fuerza; y Nakula y Sahadeva, los gemelos en que se encarnan los dioses Aśvin, también gemelos, son los dos representantes de la clase vaiśya (agricultor, comerciante) y corresponden a la tercera función, el bienestar humano y la fecundidad.

Para la Ilíada, se puede traer a colación el enfrentamiento entre Agamenón y Aquiles. Aquel, el primero entre sus iguales, se sitúa en la primera función, la soberanía y la religión; este, el mejor de los aqueos, se ubica en la segunda función, la fuerza. West (2007, p. 411; traducción del autor) apunta que "en muchas tradiciones, las narrativas sobre héroes también incluyen reyes; un rey puede ser él mismo un héroe, pero en la mayoría de los casos los roles son distintos".

En tercer lugar, el abordaje de los elementos del relato en la religión indoeuropea consiste en ponderar la materialidad discursiva de los mitos:

Se trata de someter los relatos mitológicos que conocemos al mismo tipo de análisis del relato al que se sometería un texto literario, y a partir de él agrupar dentro de un mismo tipo los relatos que nos dan componentes narrativos comunes y/o estructura interna común (Mendoza, 1995, p.134).

Así, las invariantes de la morfología heroica, como el combate y la recompensa, la muerte y el honor, el culto y la gloria, serían los elementos del relato sobre el héroe épico.
Antes de proceder a la elaboración de estas cualidades del héroe épico, conviene hacer ciertas aclaraciones acerca del héroe mítico, cuya formulación más popular, sin lugar a duda, es el viaje del héroe.

\section{El héroe mítico: el viaje del héroe}

En su célebre obra, Campbell (2006, p. 35) escribe lo siguiente: "El camino común de la aventura mitológica del héroe es la magnificación de la fórmula representada en los ritos de iniciación: separación-iniciación-retorno, que podrían recibir el nombre de unidad nuclear del monomito". Este ciclo se desglosa en diecisiete criterios funcionales, divididos en las tres etapas recién mencionadas:

Separación

1. Llamado a la aventura

2. Negativa al llamado

3. Ayuda sobrenatural

4. Cruce del primer umbral

5. Vientre de la ballena

Iniciación

6. Camino de las pruebas

7. Encuentro con la diosa

8. Mujer como tentación

9. Reconciliación con el padre

10. Apoteosis

11. Gracia última 
Retorno

12. Negativa al regreso

13. Huida mágica

14. Rescate del mundo exterior

15. Cruce del umbral de regreso

16. Posesión de los dos mundos

17. Libertad para vivir

(Campbell, 2006, pp. 53-222).

En el llamado a la aventura "una ligereza -aparentemente accidental- revela un mundo insospechado y el individuo queda expuesto a una relación con poderes que no se entienden correctamente" (Campbell, 2006, p. 54). La causa mítica de la guerra, en la Ilíada al igual que en el Mahābhārata, no es, según los valores culturales, ligera, sino grave: la afrenta a la autoridad del rey, en cuyo favor ha de acudir el héroe. Por un lado, Menelao pierde a su esposa Helena; por otro, Yudhișthira se ve privado de su ciudad Hastināpura (ambos incumplen el criterio 1).

Negar el llamado es negar la aventura (Campbell, 2006, p. 61). Si bien es cierto que la negativa es un aspecto crucial del héroe épico, esta no invalida el desarrollo de su figura: Aquiles (Ilíada I), por cólera, se niega a pelear; Arjuna (Mahābhārata $\mathrm{VI}$ ), por pena, se comporta igual (ambos cumplen el criterio 2). Más aún, la justificación es emocional en ambos casos: Aquiles quiere a su concubina Briseida; Arjuna, a sus primos los Kauravas.

Tras la aceptación del llamado, viene en el esquema, la ayuda sobrenatural: "Para aquellos que no han rechazado la llamada, el primer encuentro de la jornada del héroe es con una figura protectora" (Campbell, 2006, p. 70). Nuevamente, ambos héroes épicos reciben ayuda de los dioses, pero esto ocurre justo antes del momento crucial de la batalla: Tetis e Indra colaboran con el armamento de sus hijos, respectivamente, Aquiles y Arjuna (ambos cumplen el criterio 3). En adición, Arjuna pide explícitamente ayuda a Kṛișṇa.
Los dos últimos pasos de la etapa de separación, a saber, cruce del primer umbral y vientre de la ballena, no están presentes ni en Aquiles ni en Arjuna (ambos incumplen los criterios 4 y 5), pero sí en Odiseo y en Rāma. La explicación se encuentra en el hecho de que Aquiles y Arjuna protagonizan una épica guerrera, pero Odiseo y Rāma se mueven en una épica de aventura. En la épica guerrera, lo central es la acción bélica, esto es, el rasgo morfológico del combate, de cara a la muerte y el culto. En cambio, en la épica de aventura, lo esencial es el viaje. Así, el héroe de la épica de aventura, frente al de la épica guerrera, tiene más aspectos en común con el héroe mítico, sobre todo, en la sección que corresponde a la iniciación.

La iniciación parte del camino de las pruebas: "Una vez atravesado el umbral, el héroe se mueve en un paisaje de sueño poblado de formas curiosamente fluidas y ambiguas, en donde debe pasar por una serie de pruebas. Esta es la fase favorita de la aventura mítica" (Campbell, 2006, p. 94). Odiseo en el mar y Rāma en el bosque, Odiseo con pueblos incivilizados y Rāma con civilizaciones animales; ambos héroes épicos, en sus respectivas épicas de aventura, cumplen con estos componentes. Nuevamente, Aquiles y Arjuna no lo hacen (ambos incumplen el criterio 6).

Las pruebas más llamativas se imponen tanto a los héroes épicos como a sus esposas: mediante la prueba del arco, Odiseo se muestra digno de su esposa Penélope y Rāma aparece como merecedor de su esposa Sītā; a través de una prueba de fidelidad. Odiseo acepta a Penélope y Rāma rechaza a Sītā. En este sentido, la opinión funciona como criterio diferenciador: para Odiseo, basta su propia percepción de Penélope; para Rāma, pesa más la perspectiva de los súbditos. Así las cosas, Odiseo cumple el encuentro con la diosa; Rāma lo incumple. Del mismo modo, Odiseo cumple con el componente de la mujer como tentación (Calipso, Circe, Nausícaa) y Rāma no. No se debe olvidar que el dominio de sí mismo, función última del encuentro con la diosa, en la antigua India se obtiene por vía del ascetismo, es decir, por el camino opuesto al de la unión amorosa. 
Si tanto Odiseo como Rāma regresan a sus esposas, solo el primero se reencuentra con su padre Laertes, pues el padre Daśaratha ha muerto en ausencia de su hijo. Ahora bien, para Campbell (2006, p. 137), en este encuentro el héroe "contempla la cara del padre, comprende y los dos se reconcilian”. Sin embargo, no hay desavenencia que remediar entre Odiseo y su padre Laertes; ni siquiera la hay entre Rāma y su padre Daśaratha, quien, incluso, lo condenó al exilio. Ahora bien, si el foco de atención se mantiene en Aquiles y Arjuna, no tienen lugar, en ninguno de los dos casos, los últimos tres criterios: encuentro con la diosa, mujer como tentación y reconciliación con el padre (ambos incumplen los criterios 7, 8 y 9).

A propósito de la apoteosis, Campbell (2006) señala lo siguiente:

Este ideal es bien conocido también en el hinduismo: aquel que ha sido libertado en vida (jīvan mukta), desprovisto de deseos, compasivo y sabio, "con el corazón concentrado por el yoga, que considera todas las cosas de la misma manera, se ve a sí mismo en todos los seres y a todos los seres en sí mismo. De cualquier manera que lleve su vida, ese hombre vive en Dios" (Campbell, 2006, pp. 154-155).

Esta cita de la Bhagavad Gītā (6.29) alude al principio upanișádico de unidad entre ātman (alma individual) y brahman (alma universal). Tal objetivo de trascendencia posibilita retomar a los dos héroes épicos protagonistas de la épica guerrera: Aquiles muere como el mejor para vivir por siempre (en la Ilíada), aunque después prefiera revivir como el peor para disfrutar solo un poco (en la Odisea); Arjuna sabe que si muere por las armas llegará a un cielo temporal, pero también es consciente de que si muere con devoción trascenderá la vida y la muerte, la tierra y el cielo. Con todo, como se mencionó, las muertes de ambos héroes son poco heroicas, por lo que, en conclusión, tampoco es viable hablar de apoteosis o de gracia última (ambos incumplen los criterios $10 \mathrm{y}$ 11).

Campbell (2006, p. 179) habla, ya en la etapa del retorno, de un "trofeo trasmutador de la vida". En la épica griega, Aquiles ve frustrado su retorno, mientras que Odiseo logra volver con su esposa Penélope; en la épica sánscrita, Arjuna ve impedido su último viaje, en tanto que Rāma consigue recuperar a su esposa Sìtā. Nuevamente, las coincidencias corresponden más a la épica de aventura. La razón es evidente: la meta del héroe épico en la épica guerrera es la muerte, tras la cual el regreso queda invalidado. Así, a modo de dilema, se lo expone su madre

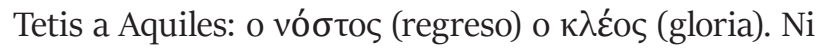
Aquiles ni Arjuna muestran la negativa al regreso, la huida mágica, el rescate del mundo exterior o el cruce del umbral de regreso (ambos incumplen los criterios $12,13,14$ y 15).

Rāma regresa por los aires en un vehículo obsequiado por los dioses, mientras que Odiseo vuelve por los mares haciendo frente a la más férrea oposición divina. A esto último se refiere Campbell (2006) cuando afirma que:

Si el trofeo ha sido obtenido a pesar de la oposición de su guardián, o si el deseo del héroe de regresar al mundo ha sido resentido por los dioses o los demonios, el último estadio del círculo mitológico se convierte en una persecución agitada y a menudo cósmica (p. 182).

A la inversa, Odiseo se encuentra con una esposa que lo ha esperado pacientemente y él le cree, pero Rāma solo ve a una esposa que ha estado mucho tiempo en compañía de otro ser masculino, se centra en la faceta negativa de la realidad. Al respecto, añade Campbell (2006, p. 201) que "el primer problema del héroe que regresa es aceptar como reales, después de la experiencia de la visión de plenitud que satisface el alma, las congojas y los júbilos pasajeros, las banalidades y las ruidosas obscenidades de la vida”.

Los últimos dos componentes durante la etapa de la reconciliación son la posesión de los dos mundos y la libertad para vivir. En este sentido, el héroe épico no posee los dos mundos; más bien, trasciende este mundo en procura del otro: Aquiles por la inmortalidad y la perfección, Arjuna por el cielo y la liberación (ambos incumplen el criterio 16). En cambio, ambos poseen libertad: Aquiles para elegir entre el regreso y la gloria, Arjuna para trascender la vida y la muerte (ambos 
cumplen el criterio 17). Así, de los diecisiete criterios, solo tres se cumplen en Aquiles y Arjuna, aunque el número resulta bastante más elevado si se atiende a Odiseo y Rāma.

En consecuencia, deviene necesario un modelo analítico diseñado específicamente para la figura del héroe, al menos del héroe épico que protagoniza una épica guerrera.

\section{El héroe épico: las doce características}

En la Grecia antigua, el héroe épico se configura en oposición al héroe lírico y al héroe trágico. La relación entre héroe épico y héroe lírico se puede rastrear en la obra de Nagy (2013, p. 93; traducción del autor), quien propone, con base en el concepto de $\kappa \lambda \varepsilon$ ć (gloria), que "Aquiles mismo no es solo un héroe épico, sino también un héroe lírico”. Sus argumentos son los siguientes: en Ilíada IX, Aquiles canta $\kappa \lambda \varepsilon^{\prime} \alpha$ ó $v \delta \rho \tilde{\omega} v$ (glorias de hombres) con el acompañamiento de una lira que había pertenecido al padre de Andrómaca; en Ilíada IX, Fénix canta $\kappa \lambda \dot{\varepsilon} \alpha$ $\alpha$ $v \delta \rho \tilde{\omega v}$ (glorias de hombres) sobre Cleopatra ("la que tiene la gloria de sus ancestros") que aplican también para Patroclo ("el que tiene la gloria de sus ancestros"); en Ístmicas VIII, Píndaro contrasta a un Aquiles muerto con un glorioso Cleandro ("gloria de los hombres"):

La canción de klea andrōn, 'glorias de héroes', cantada por Aquiles en la épica de la Ilíada (IX 189) homérica es como un eco de las canciones de lamento sobre amor y pena agridulce que se escuchan en la tradición lírica. En esta tradición, tales canciones de lamento están típicamente unidas, no solo con Aquiles, sino también con ese célebre par de amantes desdichados de la cultura musical de la Grecia antigua, a saber, Andrómaca y el hombre que se gana el odio y la furia definitivos de Aquiles en la Ilíada, Héctor. El kleos de Aquiles es una forma de canción que habita en el odio y la furia, el amor y la pena -y en el poder de la canción para expresar todos estos sentimientos intensamente líricos (Nagy, 2013, p. 96; traducción del autor).

Como es bien sabido, los géneros de la literatura griega no se suceden cronológicamente, sino que se traslapan en el tiempo y se influyen mutuamente (Rodríguez Adrados, 2012). Hay episodios líricos en la épica y episodios épicos en la lírica. La pena constituye un motivo muy productivo para este tipo de encuentros, pues se halla, incluso, en el propio nombre de Aquiles ("aquel cuyo pueblo tiene pena"). No obstante, si bien existen similitudes entre géneros literarios, en cuanto a personajes literarios pesan más las diferencias: Aquiles es un héroe épico, cuya pena evoca la lírica; Cleandro es un héroe lírico, cuya gloria evoca la épica.

A su vez, la relación entre el héroe épico y el héroe trágico ocupa una parte de las reflexiones de Miller (2000):

El protagonista trágico agoniza por actos y elecciones, se debate entre alternativas, reconoce (muy tarde) las poderosas consecuencias de un acto contaminante, de la existencia y la pena de una culpa desgarradora y de los más severos propósitos de unos dioses, en última instancia, imposibles de conocer" (p. 7; traducción del autor).

Así, el héroe trágico sería anti-épico y el héroe épico, antitrágico. El héroe épico se mueve en el plano de la certeza, del conflicto exterior, se muestra tal cual es, sirve de modelo y va dirigido a un final optimista, de acuerdo con sus méritos; en cambio, el héroe trágico se debate en la ambigüedad, la duda interior, se esconde tras la máscara, se plantea como problema e indefectiblemente, posee un carácter pesimista.

Las diferencias entre el héroe épico y el héroe lírico, por un lado, y entre el héroe épico y el héroe trágico, por otro, dificultan la aplicación de invariantes morfológicos a todos los personajes por igual. Tal problema caracteriza a una buena parte de los estudios sistemáticos sobre el héroe:

Estas primeras declaraciones [sc. Thomas Carlyle, Otto Rank, Lord Raglan, Joseph Campbell, Erich Neumann, Vladimir Propp] de carácter general suelen ser muy deductivas para mi gusto (esto es particularmente cierto de Raglan y Campbell) y su héroe está demasiado estrictamente fijado y limitado por la imagen del héroe del mito: el héroe míticamente expresado y míticamente circunscrito, un fenómeno transcultural u omnicultural, ahistórico, sincrónico y, en su núcleo más profundo, simbólico (Miller, 2000, p. 8 ; traducción del autor). 
La solución a dicho problema, según lo expuesto, está en distinguir entre los distintos tipos de héroes literarios (épico, lírico, trágico, cómico, novelístico, dramático, fabulístico, entre otros), por una parte, y el arquetipo del héroe mítico, por otra. En este sentido, Miller (2000) considera que:

Si debe haber una línea tajante entre el 'héroe en el mito’ y el ‘héroe épico’ (una línea que bien puede ser forzada), usualmente separará esa área donde operan los dioses y su 'historia cósmica' general y esa zona en la cual el hombre se yergue ostensiblemente solo en su relato o historia particular, responsable por ella y por él mismo (p. 31; traducción del autor).

Más que de un ámbito divino y un ámbito heroico, cabría hablar de una visión mítica del mundo y una visión heroica del mundo. Aquella se caracterizaría por narrativas cosmogónicas, teogónicas, antropogónicas, etiológicas y soteriológicas; esta, por narrativas heroicas y escatológicas, principalmente.

A propósito del vínculo entre mito y épica, Miller (2000) distingue entre tres tipos de épica:

$$
\begin{aligned}
& \text { 1. Épica mítica } \\
& \text { 2. Épica histórica } \\
& \text { 3. Épica mítico-histórica }
\end{aligned}
$$

(Miller, 2000, pp. 32-37, a partir de Madelénat).

La épica mítica es aquella "en la cual el héroe o los héroes centrales muestran, no solo poderes sobrehumanos o maravillosos, sino también mágicos, especialmente evidenciados en sus cambios de forma, en su vitalidad inalterable y en su velocidad sobrenatural" (Miller, 2000, pp. 32-33; traducción del autor). El ejemplo por excelencia es el Mahābhārata. Así, mientras que Aquiles y los otros héroes épicos griegos retroceden cuando los dioses así lo sugieren, Arjuna y los demás héroes indios pelean contra dioses, demonios y toda suerte de espíritus intermedios.
La épica histórica (Miller, 200o, p. 34) "se refiere de alguna manera a una estructura narrativa que describe, o al menos usa como modelos, actores y acciones reales y humanos". Su texto más característico es La Chanson de Roland. Por último, la épica mítico-histórica (Miller, 2000, p. 33; traducción del autor) está representada, paradigmáticamente, por la Ilíada: "Los héroes, especialmente los de la Ilíada, están relacionados, en el lenguaje formular, a los dioses (en tanto son llamados diogenês, esto es, 'de la sangre de Zeus')”.

La épica mítico-histórica sería, por tanto, una especie de épica intermedia entre la mítica, más próxima a los dioses, y la histórica, más próxima a los hombres. Según la visión de héroe como personaje intermedio, en realidad toda la épica estaría entre el mito y la historia: el Mahābhārata relata la guerra de Kurukșetra, tradicionalmente fechada en 3102 a.C.; la Ilíada, la guerra de Troya, habitualmente ubicada en 1184 a.C.; La Chanson de Roland, la batalla de Roncesvalles, datada en 778 d.C. En todos los casos, una base histórica, pasada por el tamiz mítico, ha dado lugar al poema épico. El héroe épico no es un personaje histórico, pero su gesta se inspira en hechos históricos.

De hecho, en la India antigua, la palabra sánscrita itihāsa designa tanto la "épica" como la "historia". Etimológicamente, es "lo que ocurrió (āsa) ciertamente (ha) así (iti)'. A diferencia de la literatura precedente, los Vedas (saber), más centrados en los dioses y sus ritos, la Itihāsa (épica) se orienta hacia los dioses y sus mitos. En adición, la voz sánscrita upakhyāna se puede referir lo mismo a un "mito" en general que a un "exemplum mítico" en particular. Etimológicamente, es "un relato (khyāna) que acompaña (ā) y está subordinado (upa)'. La Itihāsa (épica) es el género literario donde se relatan los hechos ejemplares de un vīra / śūra (héroe).

Si en lengua griega la voz que se emplea para el héroe connota lo que hace, en lengua sánscrita las palabras que se refieren al héroe remiten a lo que es. El griego ň $\rho \omega \varsigma$ (héroe) procede (Watkins, 2000: 76) del indoeuropeo ${ }^{*} s \bar{e} r-\bar{o} s-$ (protector) y, en última instancia, de la raíz ser- ${ }^{1}$ (proteger). Por el contrario, el sánscrito vīra (héroe) deriva de la raíz $V \bar{I} R$ (ser poderoso), y el sánscrito śūra (héroe), de la raíz ŚVI (hincharse). El héroe griego es 'el que protege 
(a los demás)'; el héroe indio, 'el que se hincha (por su propio poder)'. Tanto ท̌ śūra (héroe) se utilizan, en los poemas épicos, para los "guerreros" (McGrath, 2016, p. 20).

El héroe épico indoeuropeo es, en primer término, un guerrero. Miller (2000) y West (2007) ofrecen los dos estudios más recientes y completos en este sentido. Miller (2000) propone tres parámetros, con base en los cuales se pueden enumerar dieciséis aspectos:

\section{Biografía del héroe}

1. Linaje divino y nacimiento extraordinario

2. Juventud precoz

3. Reto al padre

4. Reconocimiento de los hermanos

5. Compañía para la aventura

6. Sexualidad destacada

7. Buena muerte

8. Gloria después de la muerte

\section{Aventura del héroe}

9. El espacio heroico

10. El más allá heroico

11. La búsqueda heroica

12. La política heroica

\section{Palabras del héroe}

13. Postura

\section{Armas}

16. Combate

(Reelaboración, con numeración ad hoc, a partir de Miller, 2000, pp. 70-241).

Aventura del héroe y palabras del héroe se refieren a los dos componentes esenciales del heroísmo, tal y como lo formula Fénix, en términos de "palabras" y "acciones" (Ilíada IX, p. 443). En cierto modo, Miller (2000) reformula el consabido viaje del héroe como un único aspecto del segundo parámetro, a saber, la búsqueda heroica. Así, no solo enriquece el planteamiento con la adición de elementos espaciales (dónde actúa el héroe) y políticos (con quién interactúa el héroe), sino que también complementa toda esta panorámica de las acciones heroicas con una tipología de las palabras heroicas, desarrollada, cabe destacar, en función del combate, el elemento que estaba ausente en la mayoría de las clasificaciones tradicionales.

Ahora bien, a estos ocho aspectos que integran los parámetros de acciones y palabras se suman otros ocho, de la biografía heroica: nacimiento y juventud, padres amenazadores y hermanos mesurados, compañeros masculinos y amantes femeninas, muerte bella y vida después de la muerte.

$\mathrm{Al}$ abordar las figuras de Aquiles y Arjuna desde este modelo teórico las semejanzas son bastante más numerosas que las diferencias. Antes del nacimiento de Aquiles, la diosa Tetis es dada en matrimonio a Peleo y, antes del nacimiento de Arjuna, Kuntī invoca con un mantra (fórmula) al dios Indra (ambos cumplen el aspecto 1); empero, ninguno de los dos destaca en su juventud (ambos incumplen el aspecto 2), como sí lo hacen el héroe mítico griego Heracles o el héroe mítico indio Kṛșna. Ni Aquiles ni Arjuna se enfrentan a sus padres (ambos incumplen el aspecto 3), aunque los dos cuentan con familiares menores que reconocen su autoridad (ambos cumplen el aspecto 4): Patroclo obedece a Aquiles; Nakula y Sahadeva siguen en orden de prioridad a Arjuna.

14. Gestos 
Los dos tienen un acompañante (ambos cumplen el aspecto 5): Aquiles al mismo Patroclo y Arjuna al propio Kṛșṇa, quien hace de auriga. Además, en los dos se destaca el componente sexual (ambos cumplen el aspecto 6): Aquiles toma a Briseida como botín y Arjuna gana a Draupadī como premio. Finalmente, Aquiles y Arjuna mueren de forma poco heroica (ambos incumplen el aspecto 7), aunque alcanzan la gloria y el cielo, respectivamente, tras sus muertes (ambos cumplen el aspecto 8).

En el parámetro de la aventura, Aquiles y Arjuna se mueven en un campo de batalla (ambos cumplen el aspecto 9) y alcanzan, en sus respectivas tradiciones épicas un más allá (ambos cumplen el aspecto 10). El héroe épico griego busca la inmortalidad y el héroe épico indio apunta a la liberación (ambos cumplen el aspecto 11). Los dos se contraponen a sus respectivos reyes: Agamenón y Yudhișțhira (ambos cumplen el aspecto 12). A su vez, en el parámetro de las palabras, postura, gestos y armas son descritos, tanto para Aquiles como para Arjuna, en función del combate (ambos cumplen los aspectos 13, 14, 15 y 16). En suma, se observan trece aspectos positivos frente a solo tres negativos para cada uno.

Por su parte, West (2007), en un breve apartado que dedica al héroe durante su estudio de lo indoeuropeo, formula las siguientes once cualidades, divididas por secciones:

\section{El héroe}

1. Naturaleza excepcional

2. Nacimiento e infancia

3. Hazañas de la niñez

4. Retos de grandes animales

5. Héroe en diálogo

El héroe y las mujeres

6. Conquista de la novia
7. Espada en la cama

8. Recuperación de la novia

\section{El héroe y su hijo}

9. Muerte a manos del hijo
10. Sufrimiento por el hijo

Cómo matar a un héroe

11. Punto débil

(Reelaboración, con numeración ad hoc, a partir de West, 2007, pp. 425-446).

Aquiles y Arjuna son excepcionales desde su nacimiento (ambos cumplen las cualidades 1 y 2), pero no destacan durante su niñez (ambos incumplen la cualidad 3) ni contra oponentes animales (ambos incumplen la cualidad 4). En ellos, el diálogo es igual de importante que el combate (ambos cumplen con la cualidad 5). La conquista, en su vertiente sexual, es otro rasgo común (ambos cumplen la cualidad 6), aunque en ninguno haya espada como símbolo de castidad (ambos incumplen la cualidad 7). Ahora bien, Aquiles no logra recuperar a su concubina Briseida, mientras que Arjuna solo debe recobrar el honor de su esposa Draupadī (ambos incumplen la cualidad 8).

Neoptólemo, el hijo de Aquiles, no es responsable de la muerte (incumple la cualidad 9) ni del sufrimiento (incumple la cualidad 10). Sin embargo, Abhimanyu, el hijo de Arjuna, sí mata por error a su padre (cumple la cualidad 9) y sí le produce un gran sufrimiento (cumple la cualidad 10), comparable, quizás, a la pena de Aquiles por Patroclo. Por último, pese a que los dos mueren por una flecha (ambos cumplen la cualidad 11), Aquiles deviene, por antonomasia, el representante del punto débil: el "talón de Aquiles". En síntesis, se obtienen cinco cualidades a favor y seis en contra para Aquiles, al lado de siete a favor y cuatro en contra para Arjuna.

Con base en la morfología heroica y los elementos del relato ponderados en los diversos planteamientos tradicionales y novedosos, se propone definir al héroe 
épico indoeuropeo de la épica guerrera griega y sánscrita como un personaje de naturaleza intermedia, que se rige por un código de conducta, que va en procura de un propósito inmaterial y cuya perfección final representa la piedra angular de todo el modelo. Así, se brinda la siguiente tabla, que resume las doce características del héroe épico de la épica guerrera:

TABLA 1

\section{Las doce características del héroe épico de la épica guerrera}

\begin{tabular}{|l|l|}
\hline \multirow{2}{*}{ A) Niñez y entorno familiar } & 1. Naturaleza intermedia \\
\cline { 2 - 2 } & 2. Condición elevada \\
\cline { 2 - 2 } & 3. Condición favorecida \\
\hline \multirow{2}{*}{ B) Juventud y entorno social } & 4. Código de conducta \\
\cline { 2 - 2 } & 5. Aptitudes físicas \\
\cline { 2 - 2 } & 6. Aptitudes anímicas \\
\hline C) Edad adulta y entorno militar & 7. Propósito inmaterial \\
\hline & 8. Reconocimiento general \\
\hline & 9. Reconocimiento particular \\
\hline \multirow{2}{*}{ D) Plenitud y entorno ideológico } & 10. Perfección final \\
\hline & 11. Muerte idealizada \\
\hline & 12. Vida después de la muerte \\
\hline
\end{tabular}

Fuente: Elaboración propia.

La clasificación en cuatro áreas parte del tiempo y el espacio: cuándo y dónde está el héroe. En consecuencia, el héroe se sitúa en su niñez, juventud y edad adulta. Por su muerte voluntaria y anticipada, el héroe no llega a la vejez, sino que alcanza la plenitud durante su edad adulta. Asimismo, el héroe se ubica cerca de su núcleo familiar, social y militar. Desde esta perspectiva, el héroe participa de un sistema de creencias, desde el cual se interpreta lo que sucede tras su muerte.

Para la niñez y el entorno familiar, la característica esencial es la naturaleza intermedia. Las otras dos características dependen directamente de ella: su condición es elevada con respecto a los mortales y es favorecida por parte de los inmortales. El punto de partida del héroe épico es, por tanto, compartido con el héroe mítico.
En la juventud y el entorno social, la característica fundamental es el código de conducta. A diferencia del apartado precedente, quizás este es el ámbito en que héroe épico y héroe mítico más se diferencian: aquel desarrolla una búsqueda individual, pero este participa de un acontecimiento colectivo. El código de conducta es la base del ideal heroico. Responde al qué hace que un héroe sea un héroe épico. Comprende una serie de valores culturales que rigen el modo de operar de este tipo de héroe, tanto en lo que hace como en lo que dice. Por ello, las dos características subordinadas al código de conducta son las aptitudes físicas y las aptitudes anímicas.

Durante la edad adulta y en el entorno militar, el héroe se localiza en el espacio y en el tiempo que le son propios. Las primeras dos etapas han sido solo un preámbulo 
para la tercera: niñez y familia, por un lado, y juventud y sociedad por otro, lo han moldeado como agentes externos para dar forma a su ser interno. En un planteamiento casi tautológico, el héroe épico de la épica guerrera es un guerrero. No obstante, no vive para luchar, sino que lucha para vivir. Entre la guerra y la paz, el héroe épico opta por la paz; entre la muerte y la vida, por la vida. El héroe épico es ejemplar en la medida en que el campo de batalla deviene una metáfora de la existencia, donde lo bueno y la malo, lo bello y lo feo chocan, donde tiene cabida toda la gama de emociones existentes, desde el amor hasta el odio, desde la alegría hasta el sufrimiento, y donde la pena ocupa un lugar privilegiado.

El héroe épico tiene un propósito inmaterial, el cual, a causa de su naturaleza intermedia, busca por una vía material: reconocimiento general de sus logros y reconocimiento particular de su mérito. Este propósito es, inevitablemente, paradójico. Ahora bien, tanto el héroe épico como el héroe mítico buscan algo intangible, pero aquel lo hace en una guerra y este, en una aventura.

Tras nacer, crecer y vivir, es hora de morir. El héroe épico se encuentra con la muerte durante su plenitud y dicho encuentro se halla cargado de componentes ideológicos. Las grandes religiones han respondido siempre a la pregunta por el principio y el final y, en ello, la religión indoeuropea no es la excepción. La muerte del héroe épico se concibe como el acontecimiento definitorio, como la culminación del proceso heroico, como la perfección final.

En su plenitud y desde su entorno ideológico, la perfección final, vista como parte del código de conducta, responde al tabú indoeuropeo hacia la muerte. La muerte idealizada y la vida después de la muerte son sus dos facetas. Si se idealiza la muerte, se atenúa el miedo a la muerte. Igualmente, si se visualiza un más allá, se resta y relativiza el aquí y el ahora. Así, el héroe épico es, de alguna manera, eterno. La perfección es otra cualidad que comparten el héroe épico y el héroe mítico. De hecho, trascender la muerte parece ser el eje en torno al cual giran todos los distintos tipos de figuras heroicas.

\section{Conclusiones}

Tras repasar algunos de los principales planteamientos teóricos sobre el héroe y constatar su inaplicabilidad para Aquiles y Arjuna, considerados prototípicamente héroes de la épica griega y sánscrita, respectivamente, se procedió a delimitar el concepto más particular de héroe épico. Para ello, se emplearon los postulados de la morfología heroica (Bauzá, 2004) y los elementos del relato (Mendoza, 1995), así como los análisis del héroe épico indoeuropeo (Miller, 2000; West, 2007).

Los principales aportes de la investigación son los siguientes:

1. Se propuso la distinción y la definición de varios pares de conceptos: héroe épico frente a héroe mítico, héroe épico frente a héroe lírico, héroe épico frente a héroe trágico, épica guerrera frente a épica de aventura.

2. Se elaboró una lista con doce características del héroe épico de la épica guerrera, las cuales se dividen, cronológica y espacialmente, en cuatro áreas. De las doce características, se destacaron cuatro principales, cada una de las cuales cuenta con dos subordinadas: naturaleza intermedia, código de conducta, propósito inmaterial y perfección final.

3. Se explicaron dos semejanzas y dos diferencias entre el héroe épico y el héroe mítico: unidas están la naturaleza intermedia y la perfección final, es decir, el inicio y el desenlace; separados se encuentran el objeto de la búsqueda (colectivo e individual) según un código de conducta y el ámbito de la búsqueda (guerra y aventura) con miras a un propósito inmaterial, esto es, el desarrollo de la actividad heroica. En otras palabras, héroe épico y héroe mítico coinciden en cuanto a principio y a final, pero difieren con respecto al tratamiento.

Pese a las contribuciones, es aún mucha la labor pendiente. Por ejemplo, sería pertinente emprender las siguientes investigaciones: aplicar las doce características a todos los héroes de la épica guerrera griega y sánscrita; analizar, 
desde este modelo, otros héroes épicos de épicas guerreras indoeuropeas; sintetizar las características del héroe trágico y del héroe épico para Grecia antigua, así como del héroe dramático para India antigua.

\section{Bibliografía}

Bauzá, H. (2004). El mito del héroe. Morfología y semántica de la figura heroica. México, D.F., México: Fondo de Cultura Económica.

Dumézil, G. (1977). Mito y Epopeya I. La ideología de las tres funciones en las epopeyas de los pueblos indoeuropeos. Barcelona, España: Seix Barral.

Mendoza, J. (1995). Metodología de la reconstrucción de la religión de los indoeuropeos. Ilu. o, pp. 129-140.

Miller, D. (2000). The Epic Hero. Maryland, United States: The Johns Hopkins University Press.

Nagy, G. (2013). The Ancient Greek Hero in 24 Hours. Massachusetts, United States: Harvard University Press.

Pabón, J. (1999). Diccionario manual griego-español. Barcelona, España: Vox.

Real Academia Española. (2014). Diccionario de la Lengua Española. Disponible en www.rae.es

Rodríguez Adrados, F. (2012). Préstamo e innovación en la literatura griega: épica, lírica y teatro. Myrtia. 27, pp. 13-28.

Segura, S. (2003). Nuevo diccionario etimológico latínespañol y de las voces derivadas. Bilbao, España: Universidad de Deusto.

Watkins, C. (2000). The American Heritage Dictionary of Indo-European Roots. Massachusetts, United States: Houghton Mifflin.

West, M. (2007). Indo-European Poetry and Myth. Oxford, United Kingdom: Oxford University Press. 